\title{
Glucocorticoid protects hepatoma cells against metabolic stress-induced cell death
}

\author{
YIH-HUEI UEN ${ }^{1,2}$, PIN-HAO KO ${ }^{3}$, PEN-HUI YIN ${ }^{4}$, TSUNG-YUN LIU ${ }^{3,4}$, \\ CHIN-WEN CHI ${ }^{3,4 *}$ and WING-YIU LUI ${ }^{5,6 *}$
}

\begin{abstract}
${ }^{1}$ Department of General Surgery, Chi Mei Medical Center; ${ }^{2}$ Department of Biotechnology, Southern Taiwan University, Tainan 710; ${ }^{3}$ Department and Institute of Pharmacology, School of Medicine, National Yang-Ming University; Departments of ${ }^{4}$ Medical Research and Education, and ${ }^{5}$ Surgery, Taipei Veterans General Hospital;

${ }^{6}$ Department of Surgery, School of Medicine, National Yang-Ming University, Taipei 112, Taiwan, R.O.C.
\end{abstract}

Received July 7, 2008; Accepted August 30, 2008

DOI: 10.3892/ijo_00000117

\begin{abstract}
Hepatocellular carcinoma is one of the most common cancers in the world. Previously, we found that the level of glucocorticoid receptor was significantly higher in hepatocellular carcinoma than in adjacent liver tissues. Moreover, in vitro and in vivo studies showed that glucocorticoid stimulated the growth of hepatoma cells. On the other hand, endogenous metabolites such as 2methoxyestradiol, a metabolite of estrogen produced in liver, and lactic acid, an end-product of glycolysis can result in apoptosis of tumor cells. There are studies that glucocorticoid inhibited apoptosis induced by different chemotherapeutic drugs, whether glucocorticoid could block endogenous stresses, such as 2-methoxyestradiol- or lactic acid-induced apoptosis in human and murine hepatoma cells is not known. In this study, the antagonistic effects of dexamethasone on 2-methoxyestradiol- and lactic acid-induced apoptosis were investigated in human HepG2 and murine Hepa1-6 hepatoma cells. Treatment of hepatoma cells with 2.5-10 $\mu \mathrm{M}$ 2-methoxyestradiol or $25 \mathrm{mM}$ lactic acid resulted in growth inhibition and decreased viability. In addition, results of cell cycle analysis, annexin $\mathrm{V}$ binding assay and DNA fragmentation formation showed that 2-methoxyestradiolor lactic acid-induced apoptosis of hepatoma cells but these effects were partially blocked by dexamethasone. Combined treatment of hepatoma cells with dexamethasone and 2-methoxyestradiol or lactic acid partially reduced the 2-methoxyestradiol- or lactic acid-induced apoptosis signal. Treatment of hepatoma cells with 2-methoxyestradiol or lactic acid resulted in up-regulation of caspase-8, -9 and -3 .
\end{abstract}

Correspondence to: Dr Wing-Yiu Lui, Department of Surgery, Taipei Veterans General Hospital, Taipei 112, Taiwan, R.O.C. E-mail:wylui@vghtpe.gov.tw

${ }^{*}$ Contributed equally

Key words: hepatoma, glucocorticoid, endogenous stress, protection
Dexamethasone partially suppressed the caspase expression. The Bcl-2 level was induced by dexamethasone treatment but decreased after treatment with 2-methoxyestradiol or lactic acid. These results together suggest that glucocorticoids may protect hepatoma cells from metabolic stress-induced cell damage via anti-apoptotic pathways.

\section{Introduction}

Cancer cells generate ATP by metabolizing glucose to lactic acid through glycolysis instead of oxidative phosphorylation even under aerobic condition $(1,2)$. This is one of the wellknown properties of cancer cells, the so-called 'Warburg effect'. Several genes such as HIF-1 $\alpha, p 53, A K T$ and $M Y C$ have been implicated in the molecular mechanisms that contribute to the phenomenon of aerobic glycolysis (3). However, aerobic glycolysis results in the production of large amounts of lactic acid. Cancer cells have been reported to produce 40 times more lactic acid than normal cells (4). Additionally, cancer cells grow rapidly and the supporting vasculature is often insufficient, leading to inadequate supply of oxygen and nutrition to certain regions of the tumor and waste produced by cancer cells could not be removed efficiently (5). Consequently, cancer cells are growing in a hypoxic and acidic microenvironment. Nevertheless, what mechanism supports cancer cell survival in such an adverse microenvironment is not clear.

Hepatocellular carcinoma (HCC) is one of the most common cancers in the world and is also the leading cause of death in male cancer patients in Taiwan (6). Female HCC patients not only have lower incidence and mortality but also have a better prognosis after treatment than that in male HCC patients (7-9). These observations implied that sex hormones are involved in the initiation and development of HCC $(10,11)$. Estrogen has been reported to play controversial roles in hepatocarcinogenesis. Several animal experiments showed estrogen induced or promoted liver tumor development (12-14) whereas tamoxifen, an antagonist of estrogen, decreased the incidence of chemical hepatocarcinogenesis (15). On the contrary, administration of estrogen could inhibit development of chemically induced 
a

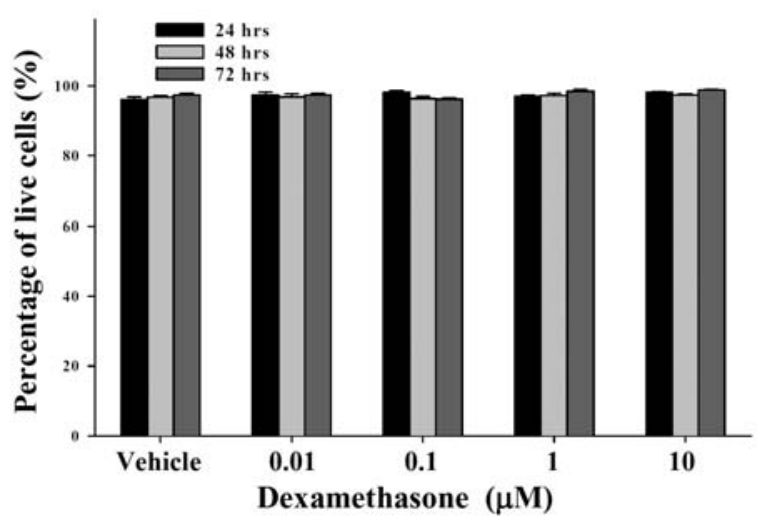

b

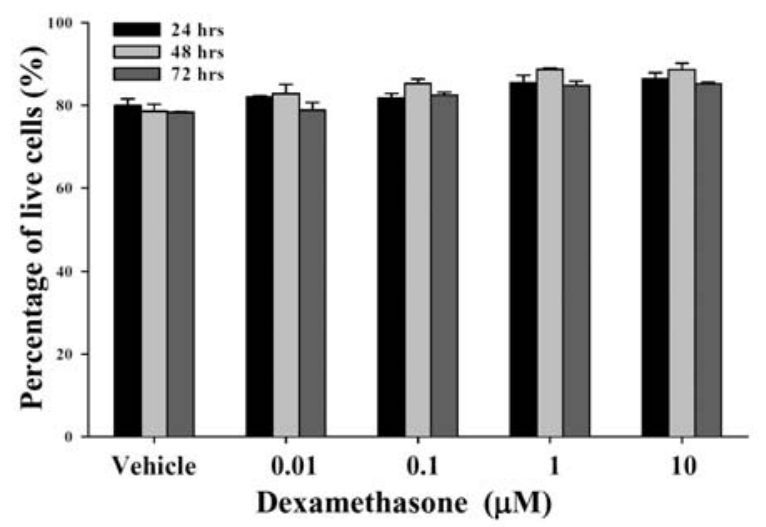

Figure 1. The effects of dexamethasone on the viability of HepG2 (a) and Hepa1-6 (b) cells as determined by trypan blue exclusion assay. Cells were treated with dexamethasone at indicated concentrations for 24, 48 and $72 \mathrm{~h}$. Ethanol (95\%) was used as vehicle, the final concentration of vehicle was <0.1\%. Data are expressed as mean \pm SD of two replicates and are representative of two independent experiments.

HCC in male mice and rats $(16,17)$. Epidemiological observation also showed number of full-term pregnancies and use of hormonal replacement therapy, which increase exposure to estrogen during adulthood, were associated with a lower risk of HCC (18). Opposite effects of estrogen metabolites in cancer cells could also explain the controversial roles of estrogen in hepatocarcinogenesis. Estrogen was firstly hydoxylated to catechol estrogens which may produce free radicals by metabolic redox cycling and in turn lead to increment of DNA mutation (19-21). In contrast, catechol O-methyltransferase in the liver can convert 2-catechol estrogen into 2-methoxyestradiol which has been shown to induce apoptosis, inhibit angiogenesis, and suppress tumor growth and metastasis (22). 2-Methoxyestradiol also inhibited growth and increased apoptosis of human hepatoma cells $(23,24)$. Therefore, the lower incidence and better survival in female HCC patients may be partially contributed to endogenous 2-methoxyestradiol. 2-Methoxyestradiol can also be considered as an endogenous metabolic stress for hepatoma cells (25).

Glucocorticoids are endogenous steroid hormones, which are necessary in mediating stress responses and they play important roles on regulation of immunological and inflammatory responses (26). Hence, synthetic derivatives of these hormones are widely used in the treatment of inflammatory diseases. However, glucocorticoids have been found to suppress serum starvation or TGF- $\beta$ or spontaneously induced apoptosis in HTC, McA-RH7777 and McA-RH8994 rat hepatoma cells, respectively (27). Additionally, our previous in vitro and in vivo studies clearly showed that glucocorticoid stimulated the growth of hepatoma cells. This glucocorticoid-stimulated growth was blocked by RU486, a glucocorticoid antagonist (28). It is well known that the effects of glucocorticoids were mediated through glucocorticoid-receptor (GR). We and others have found the level of GR and its mRNA were significantly higher in human HCC than that in the adjacent non-tumor liver tissue $(29,30)$. These results indicated that glucocorticoid and GR played an important role in regulating growth of hepatoma. However, whether glucocorticoid could also protect human and murine hepatoma cells from metabolic stress induced apoptosis is not clear.

In this study, we used lactic acid and 2-methoxyestradiol to induce apoptosis of hepatoma cells and found that glucocorticoid protected hepatoma cells against the stress-induced cell death. Increased expression of anti-apoptotic protein and reduced activities of caspases were involved in the protection effect of glucocorticoid.

\section{Materials and methods}

Cell culture. Human hepatoma HepG2 and murine Hepa1-6 cells were cultured in DMEM (Invitrogen, Carlsbad, CA, USA) containing $10 \%$ fetal bovine serum (Hyclone, Logan, UT, USA), $0.1 \mathrm{mM}$ MEM non-essential amino acid (Invitrogen) and $1 \mu \mathrm{g} / \mathrm{ml}$ gentamycin (Invitrogen). Cells were grown in a humidified $\mathrm{CO}_{2}$ incubator at $37^{\circ} \mathrm{C}$ with $95 \%$ air and $5 \% \mathrm{CO}_{2}$.

Drug treatment. Lactic acid and dexamethasone were purchased from Sigma (St. Louis, MO, USA). 2-Methoxyestradiol was purchased from Calbiochem (Darmstadt, Germany). Dexamethasone and 2-methoxyestradiol were dissolved in ethanol and DMSO, respectively. The final concentration of ethanol and DMSO were adjusted to $0.1 \%(\mathrm{v} / \mathrm{v})$, and the same amount of ethanol and DMSO were added to the control medium. Hepatoma cells were cultured in medium contained $10 \%$ charcoal stripped fetal bovine serum (Hyclone) for 3 days before drug treatment. In combination treatment groups, dexamethasone was added at $24 \mathrm{~h}$ before the treatment of lactic acid or 2-methoxyestradol. Cells were stained with trypan blue dye at a 1:1 ratio (v/v) of cells to dye and viable cells were counted with hemocytometer under a light microscope at the indicated time points.

Measurement of apoptosis. Cells were stained with annexinV-FITC to measure exposure of phosphatidylserine on the cell surface as an indicator of apoptosis, following the manufacturer's instruction (BD Biosciences, Franklin Lakes, NJ, USA). Briefly, after cells were treated with the indicated compounds, $1 \times 10^{6}$ cells were collected, washed with binding 
a

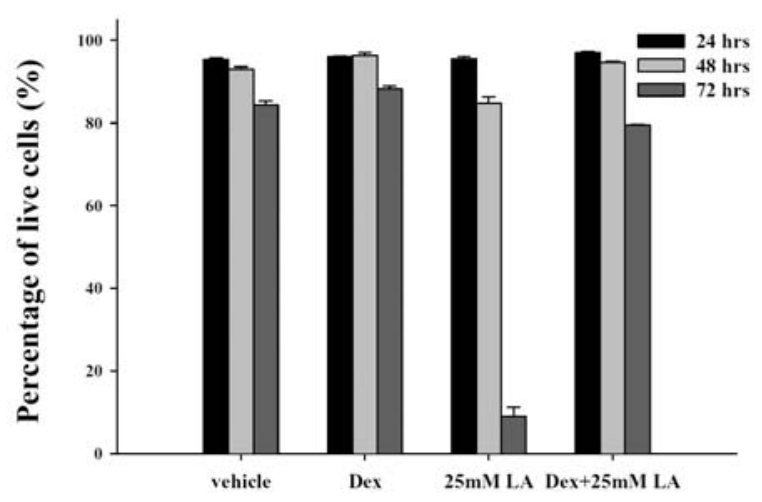

b

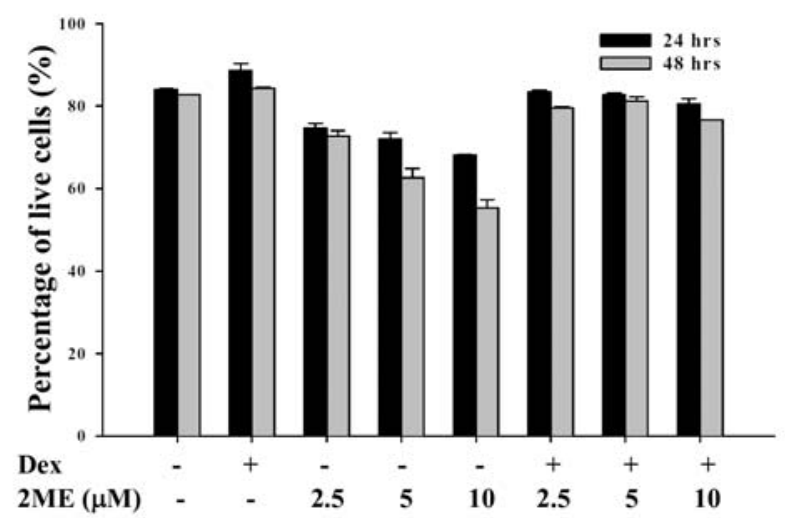

Figure 2. The effects of dexamethasone (Dex, $1 \mu \mathrm{M}$ ) and lactic acid (LA) or 2-methoxyestradiol (2-ME) on the viability of HepG2 (a) or Hepa1-6 (b) cells as determined by trypan blue exclusion assay. Cells were treated with dexamethasone and lactic acid or 2-methoxyestradiol at indicated concentrations for 24,48 and $72 \mathrm{~h}$. Ethanol (95\%) was used as vehicle, the final concentration of vehicle was $<0.1 \%$. Data are expressed as mean \pm SD of two replicates and are representative of three independent experiments.

buffer, and then resuspended in $100 \mu 1$ of the binding buffer containing $10 \mu \mathrm{l}$ of annexin-V-FITC. After $15 \mathrm{~min}$ of incubation at room temperature in the dark, the cells were washed with the binding buffer (without annexin V), resuspended in $300 \mu \mathrm{l}$ of binding buffer containing propidium iodide (PI), and then analyzed by a flow cytometer. Data acquisition and analysis were performed using a BD Biosciences FACSCalibur flow cytometer with CellQuest software. The annexin V-positive but PI-negative cells were defined as early apoptotic cells, whereas annexin V-positive and PI-positive cells are defined as late apoptotic cells. To analyze cellular DNA contents, cells were collected after drug treatment, fixed in $70 \%$ ice-cold ethanol, and kept at $-20^{\circ} \mathrm{C}$ overnight. The fixed cells were washed twice with phosphate buffered saline (PBS), stained with PI $(50 \mu \mathrm{g} / \mathrm{ml})$ in PBS containing $0.2 \%$ Tween-20 and $2.5 \mu \mathrm{g} / \mathrm{ml}$ RNase at $4^{\circ} \mathrm{C}$ overnight, and analyzed by flow cytometry. The profiles of cellular DNA contents indicate the distribution of the cells in different phases of the cell cycle and any possible DNA loss due to DNA fragmentation during apoptosis. The cell population with DNA content less than that of the $\mathrm{G}_{0} / \mathrm{G}_{1}$ cells was classified as sub- $\mathrm{G}_{0} / \mathrm{G}_{1}$ population and considered as apoptotic cells.

Caspase activity assay. Activity of caspase- 8 and -9 were determined at $8 \mathrm{~h}$ after treating the Hepa 1-6 hepatoma cells with 2.5-10 $\mu \mathrm{M}$ 2-methoxyestradiol. Caspase-3 activity was measured at $12 \mathrm{~h}$ after drug treatment. The cells were lyzed in M-PER lysis buffer (Pierce, Rockford, IL, USA) and centrifuged at $12,000 \mathrm{x}$ g for $25 \mathrm{~min}$. Assays were performed in a 96-well flat-bottomed plate. Each well $(100-\mu 1)$ contained $100 \mu \mathrm{g}$ cellular extracts, $0.2 \mathrm{mM}$ caspase substrate, 100 mM HEPES, $10 \%$ sucrose, $0.1 \%$ CHAPS, 10 mM DTT, pH 7.4. The DEVD-pNA, IETD-pNA and LEHD-pNA (Upstate Biotechnology, Lake Placid, NY, USA) were used as substrate of caspase- $3,-8$ and -9 , respectively. Absorbance was measured on a microplate reader at a wavelength of $405 \mathrm{~nm}$ after incubation at $37^{\circ} \mathrm{C}$ for $12 \mathrm{~h}$.
Western blot analysis. Cell lysates were prepared in lysis buffer containing protease inhibitor mixture (M-PER, Pierce) and centrifuged at $12,000 \times \mathrm{g}$ for $25 \mathrm{~min}$. Total protein concentration in the supernatant was measured by the Bradford protein assay (Pierce). Equal amounts of proteins $(30 \mu \mathrm{g})$ were then separated in $15 \%$ SDS-PAGE and transferred onto a nitrocellulose membrane. The membrane was blocked in TBS buffer (20 mM Tris- $\mathrm{HCl}, 150 \mathrm{mM} \mathrm{NaCl})$ with $0.1 \%$ Tween-20 and 5\% non-fat milk for $1 \mathrm{~h}$ and then incubated with primary antibody for target proteins such as procaspase-3, $-8,-9$, Bcl-2 and Bcl-xL (Santa Cruz Biotechnology, Santa Cruz, CA, USA) at $4^{\circ} \mathrm{C}$ overnight. After washing with TBS buffer with $0.1 \%$ Tween-20, the membranes were incubated with secondary anti-IgG antibody conjugated with horseradish peroxidase (Chemicon, Temecula, CA, USA) for $1 \mathrm{~h}$. The membranes were then developed with enhanced chemiluminescence system (Pierce).

Statistics. Data were obtained from duplicate samples of two to three separate experiments. Comparison between the experimental and control groups were determined using Student's t-test or one way ANOVA. Difference between the means was considered as significant at $\mathrm{P}<0.05$.

\section{Results}

Glucocorticoid protects hepatoma cells against lactic acidor 2-methoxyestradiol-induced cell death. Effects of glucocorticoid on the viability of hepatoma cells were first examined by treating cells with $0.01-10 \mu \mathrm{M}$ dexamethasone for $24-72 \mathrm{~h}$ and the cell viability were determined by the erythrosine B exclusion assay. HepG2 cells grew well in the charcoal stripped serum supplemented medium with almost $100 \%$ viability. Dexamethasone treatment had no significant effect on the viability of HepG2 cells (Fig. 1a). Nevertheless, the viability of Hepa1-6 cells was only $~ 75 \%$ after growing in the charcoal stripped serum supplemented medium while dexamethasone treatment slightly increased the viability 
a
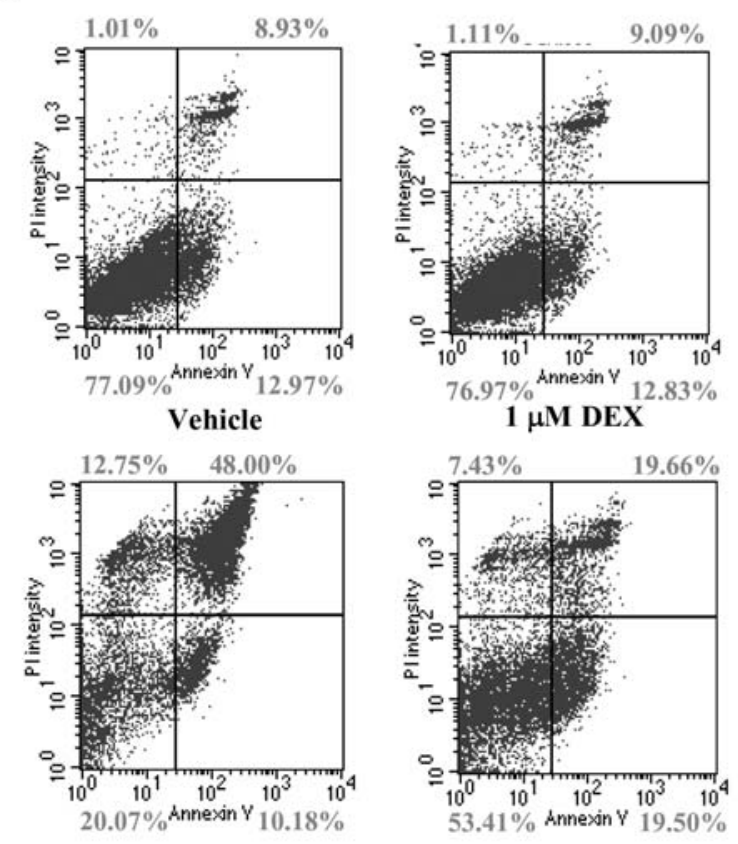

25 mM LA

$1 \mu$ M Dex +25 mM LA

\section{b}

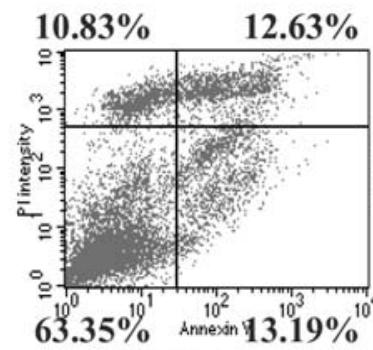

Vehicle

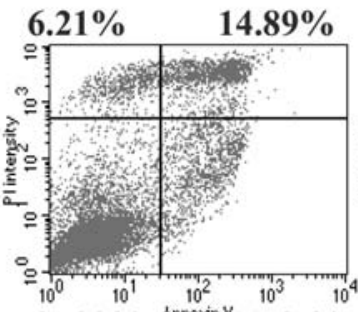

$67.23 \%$ Annexin $11.67 \%$

$1 \mu$ M Dex

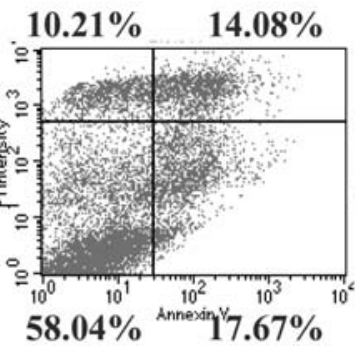

$2.5 \mu \mathrm{M} 2 \mathrm{ME}$

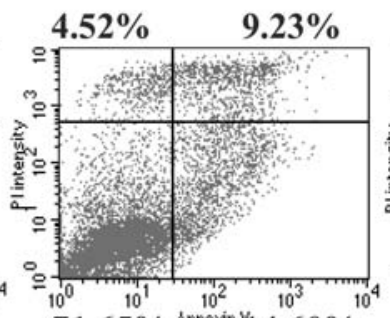

$71.65 \%^{\text {Annexin }} 14.60 \%$

$1 \mu$ M Dex

$+2.5 \mu \mathrm{M}$ 2ME

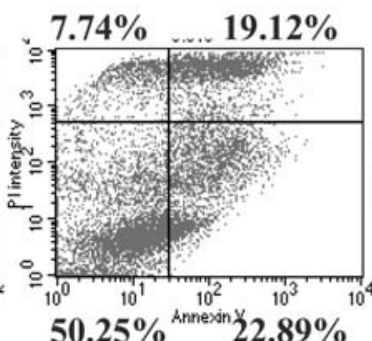

$5 \mu \mathrm{M}$ 2ME

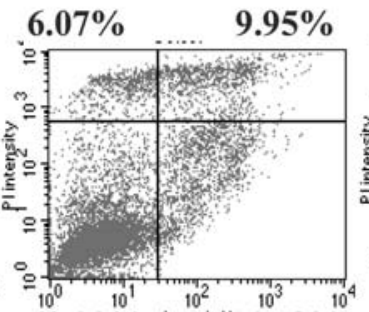

$69.20 \%$ annexin $14.78 \%$

$1 \mu$ M Dex

$+5 \mu \mathrm{M} 2 \mathrm{ME}$

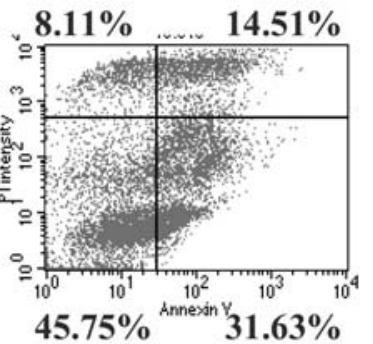

$10 \mu \mathrm{M}$ 2ME

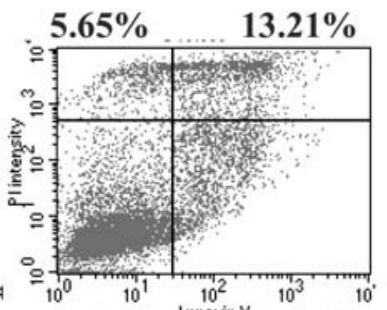

$65.33 \%{ }^{\text {Annexin }} 15.81 \%$

$1 \mu \mathrm{M}$ Dex

$+10 \mu \mathrm{M} 2 \mathrm{ME}$

Figure 3. The effects of dexamethasone (Dex) and lactic acid (LA) or 2-methoxyestradiol (2ME) induced annexin V signal on HepG2 (a) or Hepa1-6 (b) cells by flow cytometric analysis. (a) HepG2 cells were treated with vehicle control, $1 \mu \mathrm{M}$ Dex, $25 \mathrm{mM} \mathrm{LA}, 1 \mu \mathrm{M}$ Dex $+25 \mathrm{mM}$ LA for 72 h. (b) Hepa1-6 cells were treated with vehicle control, $2.5 \mu \mathrm{M} 2 \mathrm{ME}, 5 \mu \mathrm{M} 2 \mathrm{ME}, 10 \mu \mathrm{M} 2 \mathrm{ME}, 1 \mu \mathrm{M} \operatorname{Dex}, 1 \mu \mathrm{M} \operatorname{Dex}+2.5 \mu \mathrm{M} 2 \mathrm{ME}, 1 \mu \mathrm{M} \operatorname{Dex}+5 \mu \mathrm{M} 2 \mathrm{ME}, 1 \mu \mathrm{M} \operatorname{Dex}+10 \mu \mathrm{M}$ 2ME for $12 \mathrm{~h}$.

(Fig. 1b). Then, we examined the effects of dexamethasone pretreatment on stress-induced cytotoxicity. In order to mimic a metabolic stress environment of cancer cells, we cultured high density HepG2 cells in medium with exogenous lactic acid. The viability of HepG2 cells decreased after treatment with $25 \mathrm{mM}$ lactic acid at $48 \mathrm{~h}$ while almost all cells were dead at $72 \mathrm{~h}$ (Fig. 2a). Pretreatment of $1 \mu \mathrm{M}$ dexamethasone for $24 \mathrm{~h}$ prevented the lactic acid-induced cell death from 75 to $90 \%$ and almost 0 to $70 \%$ at 48 and $72 \mathrm{~h}$, respectively.
We next examined effects of dexamethasone on 2-methoxyestradiol-induced cell death in hepatoma cells. Murine Hepa1-6 cells were used to study the protection effect of dexamethasone on 2-methoxyestradiol-induced cell death because Hepa1-6 cells have been reported to be highly sensitive to this endogenous estrogen metabolite (23). Hepa1-6 cells were treated with 2.5-10 $\mu \mathrm{M}$ 2-methoxyestradiol for 24-48 h with or without pretreatment of dexamethasone. The viability of Hepa1-6 cells treated with 2-methoxyestradiol decreased in a 

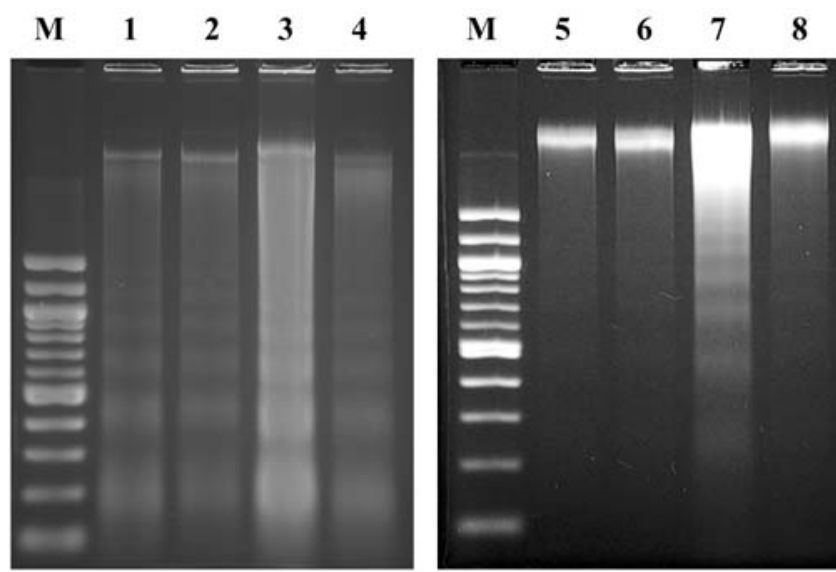

Figure 4. The effects of dexamethasone (Dex) and lactic acid (LA) or 2-methoxyestradiol (2ME) induced DNA fragmentation in hepatoma cells. HepG2 cells were treated with (1) vehicle control, (2) $1 \mu \mathrm{M}$ Dex, (3) $25 \mathrm{mM}$ LA, (4) $1 \mu \mathrm{M}$ Dex $+25 \mathrm{mM}$ LA for $72 \mathrm{~h}$. Hepa 1-6 cells were treated with (5) vehicle control, (6) $1 \mu \mathrm{M} \operatorname{Dex}$, (7) $5 \mu \mathrm{M} 2 \mathrm{ME}$, (8) $1 \mu \mathrm{M} \operatorname{Dex}+5 \mu \mathrm{M}$ 2ME for $24 \mathrm{~h}$. M indicates $100 \mathrm{bp}$ DNA marker.

dose- and time-dependent manner as compared with control while dexamethasone protected cells against 2-methoxyestradiol-induced cell death (Fig. 2b).

a

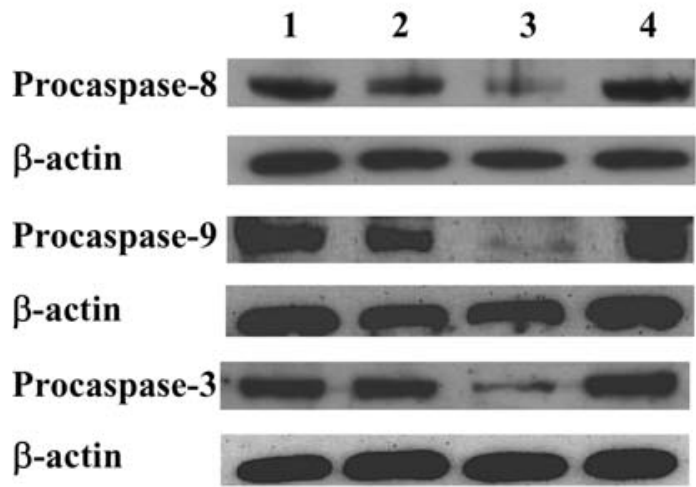

Bcl-2

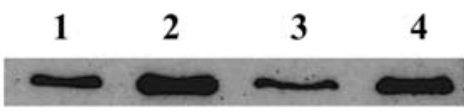

$\beta$-actin

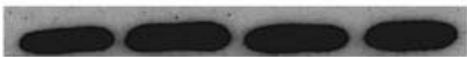

Bcl-xL

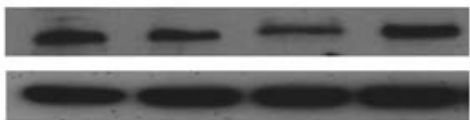

Glucocorticoid decreases lactic acid-and 2-methoxyestradiolinduced apoptosis of hepatoma cells. For apoptotic detection, DNA content analysis was performed for determination of the percentage of apoptotic cells with a sub- $G_{0} / G_{1}$ DNA content using PI staining and flow cytometry. Small amount sub- $\mathrm{G}_{0} / \mathrm{G}_{1}$ apoptotic cells in vehicle $(1.49 \%)$ and dexa(2.14\%) treated HepG2 cells were detected. Lactic (25 $\mathrm{mM}$ ) induced a significant increase to $25.13 \%$ in the 列 pub- $\mathrm{G}_{0} / \mathrm{G}_{1}$ population to $7.7 \%$. In addion, $10 \mu \mathrm{M}$ 2-methoxyestradiol treatment of Hepa 1-6 population to $18.87 \%$ as control and dexamethasone pretreatment reduced the sub- $\mathrm{G}_{0} / \mathrm{G}_{1}$ pulation to $8.56 \%$.

Further study using Annexin V binding analysis revealed ate apoptotic cells (Annexin V-FITC-positive and PI-positive (nere increased at $72 \mathrm{~h}$ after lactic acid exposure in Hepells. Dexamethasone pretreatment decreased the total apoptotic cells from 58 to 39\% (Annexin V-FITC-positive cells) and this resulted mainly from a decrease of the late apoptotic cells from 48 to $19.66 \%$ (Fig. 3a). Additionally, percentage of early apoptotic Hepa1-6 cells at $12 \mathrm{~h}$ after 2.5, 5 , and $10 \mu \mathrm{M} 2$-methoxyestradiol treatment was observed to

b

\section{$\alpha$-tubulin}

c

Bcl-xL
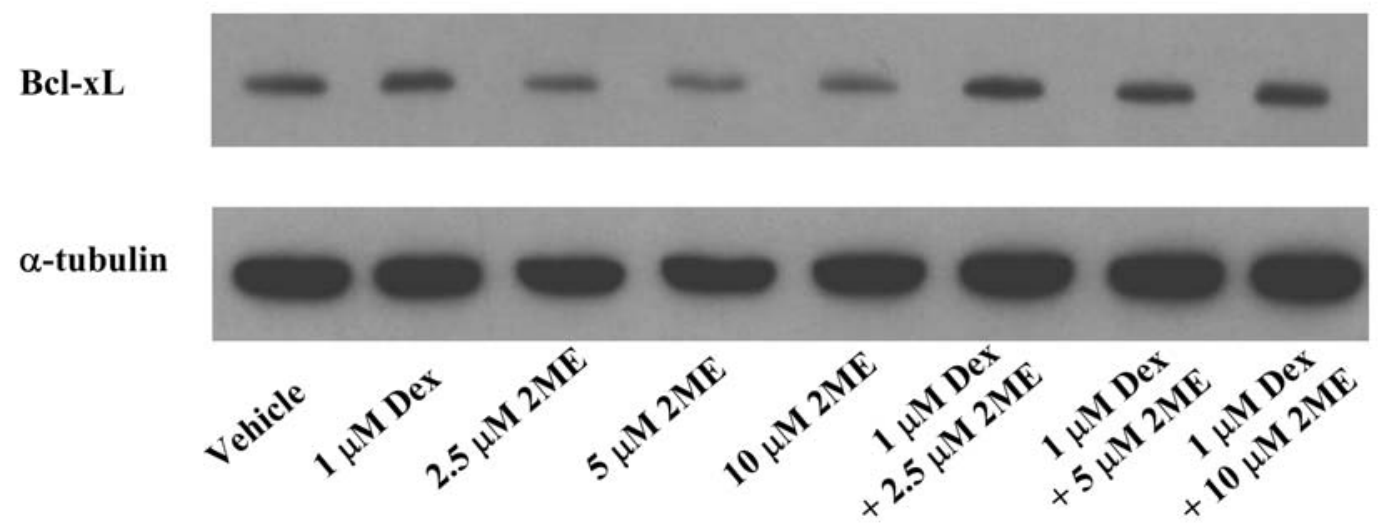

Figure 5. Western blot analysis of pro-caspase and Bcl family protein expression in hepatoma cells. (a and b) HepG2 cells were treated with (1) vehicle control, (2) $1 \mu \mathrm{M}$ Dex, (3) $25 \mathrm{mM} \mathrm{LA}$, (4) $1 \mu \mathrm{M}$ Dex $+25 \mathrm{mM}$ LA for $60 \mathrm{~h}$. (c) Hepa1-6 cells were treated with dexamethasone (Dex) and/or 2-methoxyestradiol (2ME) at indicated concentrations for $12 \mathrm{~h}$. 
a

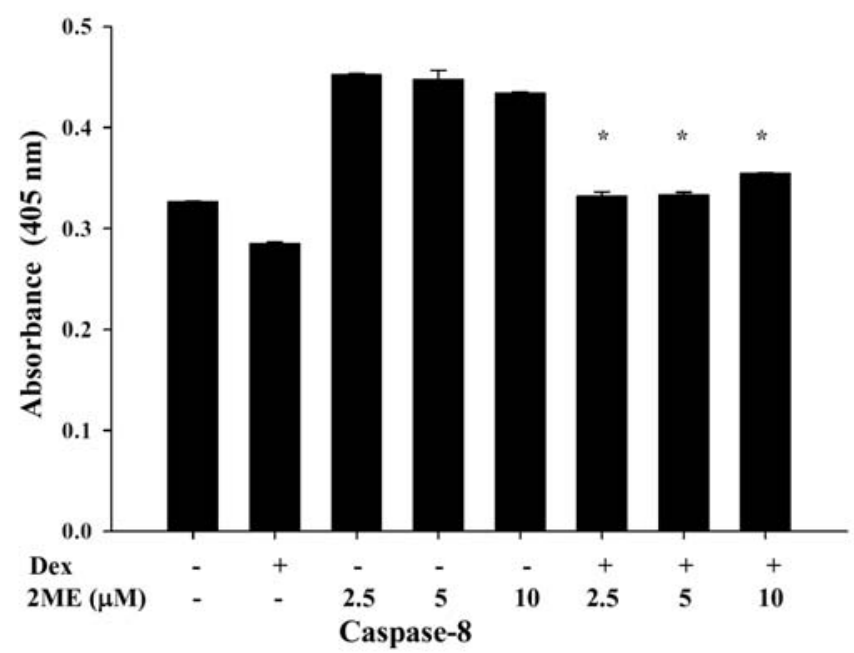

b

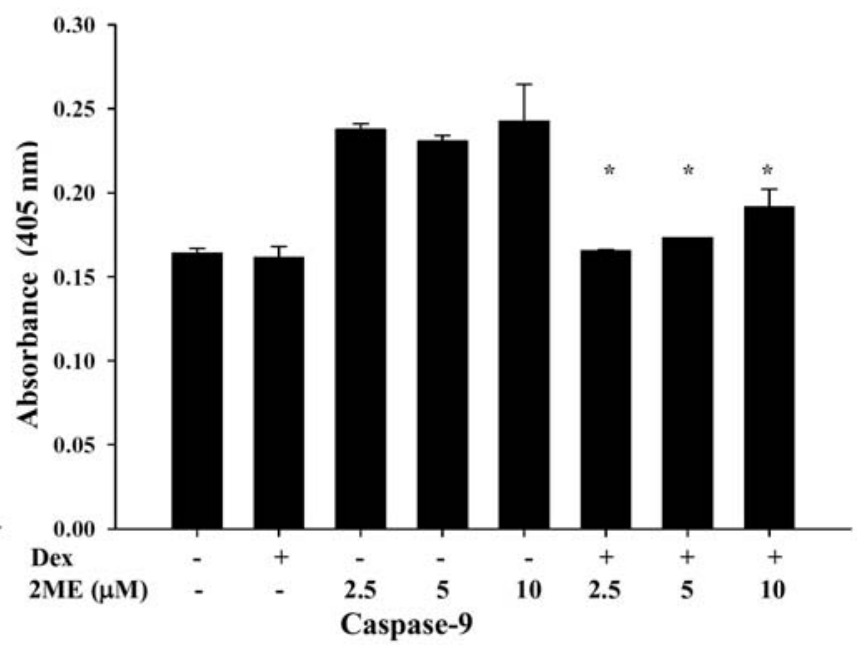

c

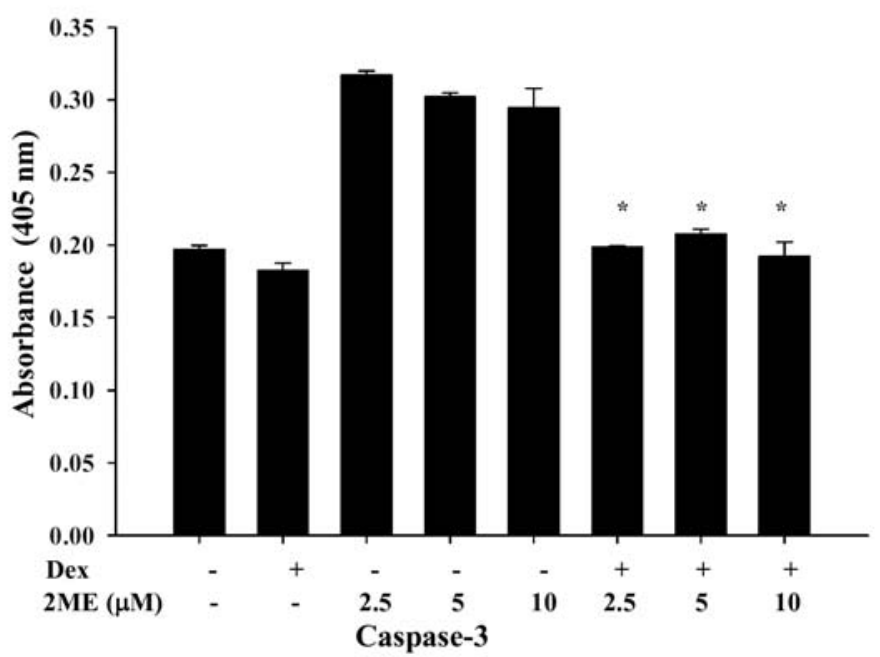

Figure 6. The caspase activity of Hepa1-6 cells. (a) The activity of caspase-8, (b) caspase-9, and (c) caspase-3. Cells were treated with dexamethasone and/or 2-methoxyestradiol (2ME) at indicated concentrations for $8 \mathrm{~h}$ on both (a) and (b), for $12 \mathrm{~h}$ on (c). Data are expressed as mean $\pm \mathrm{SD}$ of two replicates. ${ }^{*}$ Significantly different as compared to same concentration of $2 \mathrm{ME}$ but no Dex treatment. $\mathrm{P}<0.05$, one-way analysis of variance.

be increased from $13.19 \%$ of control to $17.67,22.89$ and $31.63 \%$, respectively. In dexamethasone-combined treatment groups, no matter which concentration of 2-methoxyestradiol was used, percentage of early apoptotic cells was $\sim 15 \%$ (Fig. $3 \mathrm{~b})$. Moreover, DNA fragmentation also was observed in HepG2 cells at $72 \mathrm{~h}$ after lactic acid exposure and pretreatment with dexamethasone blocked DNA fragmentation (Fig. 4). In addition, DNA fragmentation was observed in Hepa1-6 cells treated with 5 $\mu \mathrm{M}$ 2-methoxyestradiol. In cells which received combined treatment of 2-methoxyestradiol with dexamethasone, DNA fragmentation was decreased significantly (Fig. 4).

Glucocorticoid blocks lactic acid and 2-methoxyestradiolinduced-caspase activation and restores expression of Bcl-2 or $B c l-x L$. To identify the mechanism of the protection effect of dexamethasone on lactic acid- and 2-methoxyestradiolinduced apoptosis in hepatoma cells, the levels of intracellular proteins related to apoptosis, such as caspase-3, -8, -9, Bcl-2 or Bcl-xL were examined in the HepG2 or Hepa1-6 cells after lactic acid or 2-methoxyestradiol exposure with or without dexamethasone pretreatment. As shown in Fig. 5a, lactic acid induced the proteolytic cleavage of pro-caspase- $8,-9$, and -3 whereas dexamethasone prevented the lactic acid-induced proteolytic cleavage. Meanwhile, similar results were observed when Western blot analysis was performed to determine the changes in Bcl-2 and Bcl-xL. Lactic acid decreased Bcl-2 and Bcl-xL protein levels and dexamethasone prevented lactic acid-induced reduction of Bcl-2 and Bcl-xL protein (Fig. 5b). Moreover, Western blot analysis revealed treatment of 2.5-10 $\mu \mathrm{M}$ 2-methoxyestradiol resulted in reduction of Bcl-xL expression and this decrease was blocked 
by dexamethasone (Fig. 5c). In another experiment, total protein extracts were obtained for caspase activity assay after 2-methoxyestradiol treatment and the activities of caspase-3, -8 , and -9 were measured using the colorimetric substrate DEVD-pNA, IETD-pNA and LEHD-pNA, respectively. Results showed activities of both caspase- 8 and -9 were elevated at $8 \mathrm{~h}$ after 2.5-10 $\mu \mathrm{M}$ 2-methoxyestradiol treatment while the increased activities were not observed in cells pretreated with dexamethasone (Fig 6). Similar results of caspase-3 activity were observed in cells treated with 2methoxyestradiol for $12 \mathrm{~h}$.

\section{Discussion}

Induction of apoptosis through the endogenous control of death signals has been proposed to be an important process in eliminating nascent tumor cells (31). Therefore, gaining resistance to apoptosis in tumor cells is important for the development of tumor. In this study, dexamethasone prevented metabolic stress, such as lactic acid- or 2methoxyestradiol-induced cell death. Treatment of hepatoma cells with lactic acid or 2-methoxyestradiol resulted in upregulation of caspases 8,9 and 3 while dexamethasone partially suppressed the stress-induced caspase expression. The Bcl-2 level was induced by dexamethasone treatment but decreased after treatment with lactic acid or 2-methoxyestradiol. Pretreatment of hepatoma cells with dexamethasone partially reduced the lactic acid- or 2-methoxyestradiolinduced apoptosis signals. These results together with our finding of increased annexin $\mathrm{V}$ binding and DNA fragmentation after treatment of hepatoma cells with 2-methoxyestradiol or lactic acid clearly indicated that the stress-induced apoptosis of hepatoma cells could be partially blocked by glucocorticoid and resulted in increased survival.

Lactic acid is a metabolic waste generated during cell growth. It has been reported that the $\mathrm{pH}$ value in solid tumor is $~ 6.9-7.0$ (32) and the averaged lactate level in solid tumor reach up to $10 \mathrm{mM}$ or above (33). In the present study, the addition of $25 \mathrm{mM}$ lactic acid induced massive detachment of HepG2 cells and resulted in apoptosis. This mode of cell death is most likely because of loss of cell interaction with extracellular matrix which is considered as anoikis. Similar observation has been found in ouabain-treated Madin-Darby canine kidney cells (34). Glucocorticoid has been reported to affect focal adhesion of osteoblasts. Cho et al have found that short-term glucocorticoid treatment had no significant effect on focal adhesion kinase or its signaling, but one-week long dexamethasone treatment resulted in changes in these signaling pathways (35). In contrast, methylprednisolone treatment of isolated human hepatocytes had no significant effects on cell attachment at the time of cell plating (36). Glucocorticoid has both pro-apoptotic and anti-apoptotic actions depending on tissue specificity. In solid tumor, the glucocorticoid-induced survival of epithelial cells and carcinoma cells is frequently observed. The glucocorticoidinduced changes in intracellular signaling pathways may contribute significantly to attachment to the extracellular matrix and cell-cell contacts affecting survival (37). Therefore, our finding that dexamethasone not only effectively blocked the lactic acid-induced cell death of HepG2 cells (Fig. 2a) but also blocked the 2-methoxyestradiol-induced apoptosis of Hepa1-6 hepatoma cells (Fig. 2b) supports the hypothesis that dexamethasone interacts with the drug-induced apoptosis pathways and cell attachment.

Glucocorticoids possess antihypersensitivity activity and are often employed as antiemetics during chemotherapy (38). However, the use of glucocorticoids has been found to protect tumor cells from chemotherapy-induced apoptosis in various cell types including breast, cervix, colorectal, gastric, hepatocellular and lung tumors (39-42). The detailed mechanism is not clear. One possibility is that glucocorticoid treatment modulated the signaling pathways of apoptosis. It has been reported that 2-methoxyestradiol-induced apoptosis of breast cancer cells was mediated by the activation of caspases 3,8 , and 9 (43). In this study, a similar observation was found in hepatoma cells (Figs. 5 and 6). It is interesting that dexamethasone treatment blocked the activation of caspases in both cell lines suggesting that dexamethasone probably blocked the upstream regulators of this apoptotic pathway and its detailed mechanism needs further investigation. Alternatively, Bcl-2 and Bcl-xL are also involved in the regulation of apoptosis (44). Treatment of human or rat hepatocytes with dexamethasone increased the level of Bcl-xL and/or Bcl-2, respectively (45). Our results showed that the levels of Bcl-xL and/or Bcl-2 were reduced after treatment with either 2-methoxyestradiol or lactic acid (Fig. 5a and b) and this reduction was blocked by dexamethasone suggesting that Bcl-2 family may be important targets of dexamethasone in blocking apoptosis. Our results corresponded well with the observation that activation of $\mathrm{NF}-\kappa \mathrm{B}$ or increased expression of $\mathrm{Bcl}-\mathrm{xL}$ is involved in glucocorticoid protection effects on serum starvation-induced apoptosis of rat hepatoma cells (46). These results together suggest that glucocorticoid regulated the anti-apoptotic signaling pathway in hepatoma cells and increased their survival.

\section{Acknowledgements}

This work was supported in part by a Grant (CMYM9402) from the Chi-Mei Medical Center and National Yang-Ming University and Grant No. NSC 96-2314-B-075-011 from the National Science Council, Taiwan, Republic of China.

\section{References}

1. Warburg O: On the origin of cancer cells. Science 123: 309-314, 1956

2. Gatenby RA and Gillies RJ: Why do cancers have high aerobic glycolysis? Nat Rev Cancer 4: 891-899, 2004.

3. Kim JW and Dang CV: Cancer's molecular sweet tooth and the Warburg effect. Cancer Res 66: 8927-8930, 2006.

4. Holm E, Hagmuller E, Staedt U, et al: Substrate balances across colonic carcinomas in humans. Cancer Res 55: 1373-1378, 1995.

5. Cairns R, Papandreou I and Denko N: Overcoming physiologic barriers to cancer treatment by molecularly targeting the tumor microenvironment. Mol Cancer Res 4: 61-70, 2006.

6. Department of Health, Executive Yuan, Republic of China (Taiwan): Statistics of Causes of Death, 2007.

7. Jwo SC, Chiu JH, Chau GY, Loong CC and Lui WY: Risk factors linked to tumor recurrence of human hepatocellular carcinoma after hepatic resection. Hepatology 16: 1367-1371, 1992.

8. Jan CF, Chen CJ and Chen HH: Causes of increased mortality from hepatocellular carcinoma in high incidence country: Taiwan experience. J Gastroenterol Hepatol 20: 521-526, 2005. 
9. Tangkijvanich P, Mahachai V, Suwangool P and Poovorawan Y: Gender difference in clinicopathologic features and survival of patients with hepatocellular carcinoma. World J Gastroenterol 10: 1547-1550, 2004.

10. Lui WY, P'eng FK, Liu TY and Chi CW: Hormonal therapy for hepatocellular carcinoma. Med Hypotheses 36: 162-165, 1991.

11. Giannitrapani L, Soresi M, La Spada E, Cervello M, D'Alessandro $\mathrm{N}$ and Montalto G: Sex hormones and risk of liver tumor. Ann N Y Acad Sci 1089: 228-236, 2006.

12. Yager JD Jr and Yager R: Oral contraceptive steroids as promoters of hepatocarcinogenesis in female Sprague-Dawley rats. Cancer Res 40: 3680-3685, 1980.

13. Coe JE, Ishak KG and Ross MJ: Estrogen induction of hepatocellular carcinomas in Armenian hamsters. Hepatology 11: 570-577, 1990 .

14. Porter LE, Van Thiel DH and Eagon PK: Estrogens and progestins as tumor inducers. Semin Liver Dis 7: 24-31, 1987.

15. Di Bisceglie AM, Osmack P and Brunt EM: Chemoprevention of hepatocellular carcinoma: use of tamoxifen in an animal model of hepatocarcinogenesis. J Lab Clin Med 145: 134-138, 2005.

16. Shimizu I, Yasuda M, Mizobuchi Y, et al: Suppressive effect of oestradiol on chemical hepatocarcinogenesis in rats. Gut 42: 112-119, 1998.

17. Nakatani T, Roy G, Fujimoto N, Asahara T and Ito A: Sex hormone dependency of diethylnitrosamine-induced liver tumors in mice and chemoprevention by leuprorelin. Jpn J Cancer Res 92: 249-256, 2001.

18. Yu MW, Chang HC, Chang SC, et al: Role of reproductive factors in hepatocellular carcinoma: Impact on hepatitis B- and C-related risk. Hepatology 38: 1393-1400, 2003.

19. Liehr JG and Roy D: Free radical generation by redox cycling of estrogens. Free Radic Biol Med 8: 415-423, 1990.

20. Yager JD and Liehr JG: Molecular mechanisms of estrogen carcinogenesis. Annu Rev Pharmacol Toxicol 36: 203-232, 1996.

21. Hiraku Y, Yamashita N, Nishiguchi M and Kawanishi S: Catechol estrogens induce oxidative DNA damage and estradiol enhances cell proliferation. Int J Cancer 92: 333-337, 2001.

22. Fotsis T, Zhang Y, Pepper MS, et al: The endogenous oestrogen metabolite 2-methoxyoestradiol inhibits angiogenesis and suppresses tumour growth. Nature 368: 237-239, 1994.

23. Lin HL, Liu TY, Chau GY, Lui WY and Chi CW: Comparison of 2-methoxyestradiol-induced, docetaxel-induced, and paclitaxelinduced apoptosis in hepatoma cells and its correlation with reactive oxygen species. Cancer 89: 983-994, 2000.

24. Schumacher G, Scheunert S, Rueggeberg A, et al: A very low toxic agent induces apoptosis and reduces growth of human hepatocellular carcinoma cells. J Gastroenterol Hepatol 21: 1207-1212, 2006.

25. Lui WY, Lin HL, Chau GY, Liu TY and Chi CW: Male predominance in hepatocellular carcinoma: new insight and a possible therapeutic alternative. Med Hypotheses 55: 348-350, 2000.

26. Sapolsky RM, Romero LM and Munck AU: How do glucocorticoids influence stress responses? Integrating permissive, suppressive, stimulatory, and preparative actions. Endocr Rev 21: 55-89, 2000.

27. Yamamoto M, Fukuda K, Miura N, Suzuki R, Kido T and Komatsu Y: Inhibition by dexamathasone of transforming growth factor $\beta_{1}$-induced apoptosis in rat hepatoma cells: a possible association with Bck-xL induction. Hepatology 27: 959-966, 1998.
28. Lui WY, Chi CW, Chang YF, et al: In vivo and in vitro growth stimulation of murine hepatoma cells by glucocorticoid. Anticancer Res 22: 1413-1422, 2002.

29. P'eng F K, Lui WY, Chang TJ, et al: Glucocorticoid receptors in hepatocellular carcinoma and adjacent liver tissue. Cancer 62: 2134-2138, 1988.

30. Lui WY, P'eng F K, Chang YF, et al: Analysis of glucocorticoid receptors in human hepatocellular carcinoma and HepG2 cells. Hepatology 18: 1167-1174, 1993.

31. Schulte-Hermann R, Bursch W, Low-Baselli A, Wagner A and Grasl-Kraupp B: Apoptosis in the liver and its role in hepatocarcinogenesis. Cell Biol Toxicol 13: 339-348, 1997.

32. Vaupel P, Kallinowski F and Okunieff P: Blood flow, oxygen and nutrient supply, and metabolic microenvironment of human tumors: a review. Cancer Res 49: 6449-6465, 1989.

33. Gullino PM, Clark SH and Grantham FH: The interstitial fluid of solid tumors. Cancer Res 24: 780-794, 1964.

34. Akimova OA, Poirier M, Kotelevtsev SV, Hamet P and Orlov SN: The death of ouabain-treated renal epithelial cells: evidence against anoikis occurrence. Apoptosis 13: 670-680, 2008.

35. Cho P, Schneider GB, Kellogg B, Zaharias R and Keller JC: Effect of glucocorticoid-induced osteoporotic-like conditions on osteoblast cell attachment to implant surface microtopographies. Implant Dent 15: 377-385, 2006.

36. Serrano T, Mitry RR, Terry C, Lehec SC, Dhawan A and Hughes RD: The effects of immunosuppressive agents on the function of human hepatocytes in vitro. Cell Transplant 15: 777-783, 2006.

37. Herr I, Gassler N, Friess H and Buchler MW: Regulation of differential pro- and anti-apoptotic signaling by glucocorticoids. Apoptosis 12: 271-291, 2007.

38. The Italian Group for Antiemetic Research: Dexamethasone alone or in combination with ondansetron for the prevention of delayed nausea and vomiting induced by chemotherapy. N Engl J Med 342: 1554-1559, 2000.

39. Amsterdam A, Tajima K and Sasson R: Cell-specific regulation of apoptosis by glucocorticoids: implication to their antiinflammatory action. Biochem Pharmacol 64: 843-850, 2002.

40. Herr I, Ucur E, Herzer K, et al: Glucocorticoid cotreatment induces apoptosis resistance toward cancer therapy in carcinomas. Cancer Res 63: 3112-3120, 2003.

41. Zhang C, Kolb A, Mattern J, et al: Dexamethasone desensitizes hepatocellular and colorectal tumours toward cytotoxic therapy. Cancer Lett 242: 104-111, 2006.

42. Zhang C, Wenger T, Mattern J, et al: Clinical and mechanistic aspects of glucocorticoid-induced chemotherapy resistance in the majority of solid tumors. Cancer Biol Ther 6: 278-287, 2007.

43. LaVallee TM, Zhan XH, Herbstritt CJ, Kough EC, Green SJ and Pribluda VS: 2-Methoxyestradiol inhibits proliferation and induces apoptosis independently of estrogen receptors alpha and beta. Cancer Res 62: 3691-3697, 2002.

44. Adams JM and Cory S: The Bcl-2 protein family: arbiters of cell survival. Science 281: 1322-1326, 1998.

45. Bailly-Maitre B, de Sousa G, Boulukos K, Gugenheim J and Rahmani R: Dexamethasone inhibits spontaneous apoptosis in primary cultures of human and rat hepatocytes via $\mathrm{Bcl}-2$ and Bcl-xL induction. Cell Death Differ 8: 279-288, 2001.

46. Evans-Storms RB and Cidlowski JA: Delineation of an antiapoptotic action of glucocorticoids in hepatoma cells: the role of nuclear factor-kappaB. Endocrinology 141: 1854-1862, 2000 . 